\title{
Minimal extrathyroidal extension does not affect survival of well-differentiated thyroid cancer
}

\author{
Zaid Al-Qurayshi1,*, Mohamed A Shama2,3,*, Gregory W Randolph4 and Emad Kandil2 \\ 1Department of Otolaryngology - Head \& Neck Surgery, University of lowa Hospitals and Clinics, lowa City, lowa, USA \\ 2Department of Surgery, School of Medicine, Tulane University, New Orleans, Louisiana, USA \\ ${ }^{3}$ Department of Head and Neck Surgical Oncology, NCl, Cairo University, Cairo, Egypt \\ ${ }^{4}$ Division of Thyroid and Parathyroid Surgery, Department of Otolaryngology, Massachusetts Eye and Ear Infirmary, \\ Boston, Massachusetts, USA \\ *(Z Al-Qurayshi and M A Shama contributed equally to this work)
}

Correspondence should be addressed to E Kandil

Email

Ekandil@tulane.edu

\begin{abstract}
Differentiated thyroid cancer (DTC) with minimal extrathyroidal extension (MEE) is classified as stage III regardless of the tumor size. In this study, we aim to examine the effect of MEE on the overall survival and management of this population. A retrospective cohort study was performed, which utilized the National Cancer Database (NCDB), 20042012. The study population included patients, aged $\geq 45$ years, who underwent surgery for DTC (pT3NOM0) with MEE compared to that in patients with pT2NOMO. A total of 9556 patients were included. These were divided into four groups, 4410 patients with pT2NOMO (Group 1: T $\leq 4 \mathrm{~cm}$ without MEE), 3274 with pT3NOMO (Group 2: $\mathrm{T} \leq 4 \mathrm{~cm}$ with MEE), 447 with pT3NOMO (Group 3: T $>4 \mathrm{~cm}$ with MEE) and 1430 patients with pT3NOMO without MEE (Group 4: T> $4 \mathrm{~cm}$ without MEE). Median follow-up time was 46.7 months (interquartile range: $27.8-72.1)$. Patients in Group 2 ( $T \leq 4 \mathrm{~cm}$ with $\mathrm{MEE}$ ) had no significant worse survival compared to patients in Group $1(T \leq 4 \mathrm{~cm}$ without MEE) $(P=0.85)$, whereas Groups 3 and $4(T>4 \mathrm{~cm})$, both had significantly lower survival $(P<0.001)$ with no difference between the two groups. Total thyroidectomy was associated with improved overall survival compared to that in lobectomy in Group 4 ( $T>4 \mathrm{~cm}$ without MEE). Radioiodine utilization was associated with improved survival only with tumors larger than $4 \mathrm{~cm}$ with or without MEE. In DTC patients aged older than 45 years of age with tumor size less than $4 \mathrm{~cm}$, MEE has no survival significance. Tumor size is an independent prognostic marker regardless of MEE status. Our data support re-evaluation of the current staging system.
\end{abstract}

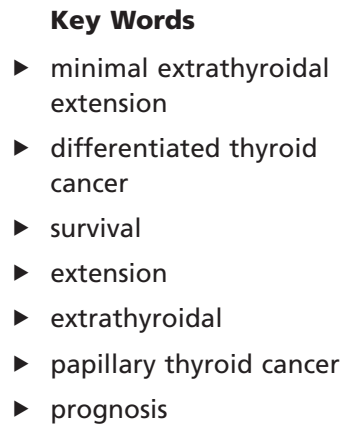

\section{Introduction}

Thyroid capsule invasion by the primary tumor is suggested to reflect disease prognosis (Edge \& Carducci 2009, Machens \& Dralle 2015). Extrathyroid extension was initially described as a poor prognostic factor in 1961
(Woolner et al. 1961). Gross extrathyroid extension, classified as T4 since the first edition of AJCC, is a predictor of tumor recurrence and mortality (Sugitani et al. 2004, Edge \& Carducci 2009, Ito et al. 2012, Verburg et al. 2013). 
Minimal extrathyroid extension (MEE) was introduced to the staging system at 2002, the sixth edition of AJCC. MEE includes extension to sternothyroid muscle or perithyroid soft tissue and is classified as T3 and consequently, upstages $\mathrm{T} 1$ and $\mathrm{T} 2$ differentiated thyroid cancer (DTC) patients aged older than 45 years to stage III disease (Edge \& Carducci 2009). Upstaging appears to affect the decisions involving the extent of resection and radioactive iodine therapy (RAI) (Haugen et al. 2016, Ruel et al. 2016). Impact of MEE on the survival is a controversial topic and was investigated by different single institution studies mostly from Asia (Ito et al. 2006a,b, Hotomi et al. 2012, Shin et al. 2013). Herein, the study sought to investigate the impact of MEE on survival in DTC patients aged older than 45 years and NO in relation to the size of concomitant thyroid tumor.

\section{Methods}

The study is a retrospective cohort analysis utilizing the National Cancer Data Base (NCDB), 2004-2012. The NCDB is a joint program of the Commission on Cancer of the American College of Surgeons (ACS) and the American Cancer Society. The NCDB, established in 1989, is a nationwide, facility-based, comprehensive clinical surveillance resource oncology data set that currently captures $70 \%$ of all newly diagnosed malignancies in the United States annually. The NCDB is de-identified data that are exempted from approval of the institutional review board ((https://www.facs.org/quality-programs/ cancer/ncdb) Accessed October 15, 2015).

The primary study objective is to assess the impact of tumor size and MEE on the overall survival in patients with DTC. The secondary study objective is to assess the

Table 1 Descriptive statistics of the study population based on stage, minimal extrathyroidal extension and tumor size.

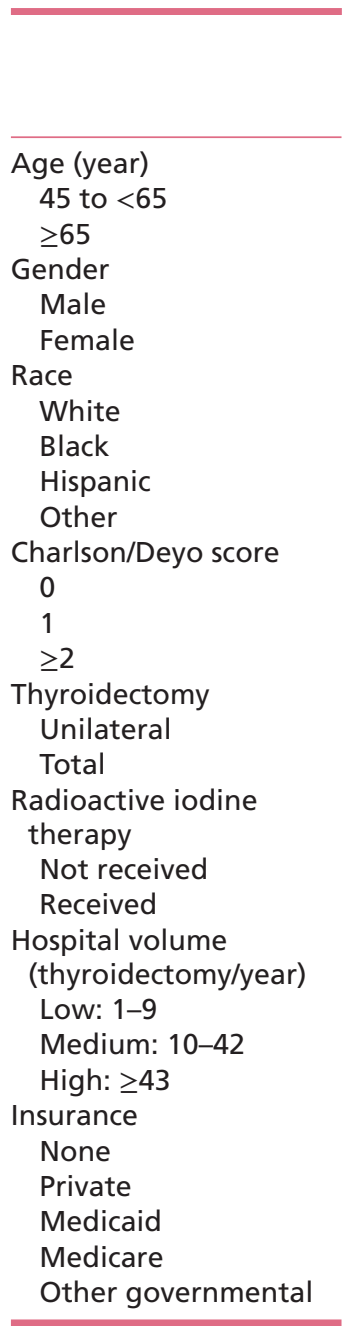

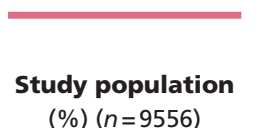

(\%) $(n=9556)$

74.5

25.5

26.6

73.5

85.5

8.4

0.8

5.3

81.7

15.4

2.9

14.4

85.6

30.1

69.9

29.0

46.8

24.3

\section{4}

67.2

4.3

25.2

aChi-square test.

MEE, minimal extrathyroidal extension.

\begin{tabular}{|c|c|c|c|c|}
\hline \multicolumn{4}{|c|}{ Differentiated thyroid carcinoma stage (\%) } & \multirow[b]{2}{*}{$\mathbf{P a}$} \\
\hline $\begin{array}{l}\text { pT2NOMO } \\
(n=4410)\end{array}$ & $\begin{array}{l}\text { pT3NOMO, MEE, size } \\
\leq 4 \mathrm{~cm}(n=3274)\end{array}$ & $\begin{array}{l}\text { pT3NOM0, MEE, size } \\
>4 \mathrm{~cm}(n=442)\end{array}$ & $\begin{array}{l}\text { pT3NOM0, no MEE, } \\
\text { size }>4 \mathrm{~cm}(n=1430)\end{array}$ & \\
\hline 77.2 & 74.7 & 61.5 & 69.8 & \\
\hline 22.8 & 25.3 & 38.5 & 30.2 & $<0.001$ \\
\hline 26.0 & 19.6 & 40.3 & 39.8 & \\
\hline 74.0 & 80.4 & 59.7 & 60.2 & $<0.001$ \\
\hline 86.1 & 88.2 & 80.8 & 78.7 & \\
\hline 8.5 & 4.8 & 11.8 & 15.5 & \\
\hline 0.8 & 0.8 & 1.4 & 0.9 & \\
\hline 4.7 & 6.2 & 6.1 & 4.9 & $<0.001$ \\
\hline 83.4 & 81.4 & 77.8 & 78.5 & \\
\hline 13.9 & 15.9 & 18.6 & 18.0 & \\
\hline 2.8 & 2.8 & 3.6 & 3.5 & $<0.001$ \\
\hline 16.6 & 8.8 & 19.9 & 18.9 & \\
\hline 83.5 & 91.2 & 80.1 & 81.1 & $<0.001$ \\
\hline 31.7 & 28.0 & 30.1 & 30.1 & \\
\hline 68.3 & 72.1 & 69.9 & 69.9 & 0.006 \\
\hline 29.8 & 27.2 & 39.1 & 27.1 & \\
\hline 47.1 & 46.3 & 48.0 & 46.5 & \\
\hline 23.1 & 26.5 & 12.9 & 26.4 & $<0.001$ \\
\hline 2.0 & 2.2 & 3.4 & 3.9 & \\
\hline 70.2 & 67.7 & 52.7 & 61.1 & \\
\hline 4.1 & 3.9 & 6.3 & 5.0 & \\
\hline 22.5 & 25.6 & 36.0 & 29.2 & \\
\hline 1.2 & 0.7 & 1.6 & 0.8 & $<0.001$ \\
\hline
\end{tabular}


survival benefit of total thyroidectomy vs lobectomy and utilization of RAI vs no utilization in patients with MEE. We focused on the group $<4 \mathrm{~cm}$ as these may not receive aggressive surgery or RAI treatment based on their size (unless MEE is judged significant and warranting such aggressive treatment) based on the most recent American Thyroid Association (ATA) guidelines (Haugen et al. 2016).

The study population included adult patients (age $\geq 45$ years) who underwent thyroidectomy and had a diagnosis DTC based on International Classification of Diseases for Oncology third edition (ICD-O-3: 8050, 8260, 8340, 8341, 8342, 8343, 8344, 8330, 8331, 8332, 8335, 8450). Subsequently, the study population classified into control who had a pathological stage of pT2NOM0 (Group 1) and cases who had a pathological stage of pT3NOMO as coded by the database based on pathological examination. Tumor size of $4 \mathrm{~cm}$ was further used to categorize cases into $\leq 4 \mathrm{~cm}$ with MEE (Group 2), $>4 \mathrm{~cm}$ with MEE (Group 3) and $>4 \mathrm{~cm}$ without MEE (Group 4). The choice of this cutoff value is based on the American Joint Committee on Cancer (AJCC 7th edition) Staging System (Edge \& Carducci 2009).

Other independent factors that were considered for their confounding effect included: age (45 to $<65$, $\geq 65$ ), gender, race (white, black, Hispanic and other), Charlson/Deyo comorbidity score as coded by the database $(0,1$ and $\geq 2)$, hospital volume classification followed quartile classification based on the total number of thyroidectomies performed per year (low: $\leq 25$ th percentile: 1-9 thyroidectomies/year, intermediate: $>25$ th to $\leq 75$ th percentile: $10-42$ thyroidectomies/year and high: $>75$ th percentile: $\geq 43$ thyroidectomies/year) and type of insurance as coded in the database (none, private, Medicaid, Medicare and other governmental).

Chi-square test was used to compare the baseline characteristics among the study groups. Kaplan-Meier curve and log-rank test were used to assess the association of each independent risk factor for the overall survival, and factors with significant association were considered confounders and were included in the multivariate model. Cox hazard ratio model was used to assess the time interaction term and calculate adjusted hazard ratio (HR) and 95\% confidence interval (95\% CI). Significant level was set as $P=0.05$. All statistical analyses were performed using SAS 9.4 (SAS Institute Inc., Cary, NC, USA.).

\section{Results}

A total of 9556 patients were included in our study, 4410 patients in Group 1 ( $\mathrm{T} \leq 4 \mathrm{~cm}$ without MEE), 3274 in
Group 2 ( $\mathrm{T} \leq 4 \mathrm{~cm}$ with MEE) and 447 in Group 3 ( $\mathrm{T}>4 \mathrm{~cm}$ with MEE) and 1430 patients in Group $4(\mathrm{~T}>4 \mathrm{~cm}$ without MEE).

Most of the study population were white $(85.5 \%)$, female $(73.5 \%)$ and had private insurance (67.2\%). Most patients did not have other comorbidities at the time of admission (81.7\%) (Table 1).

Median follow-up time was 46.7 months (interquartile range: 27.8-72.1). After adjusting for patient age, gender, race, Charlson/Deyo score, type of thyroidectomy, RAI therapy status, hospital volume and insurance type, the presence of MEE in Group 2 ( $\mathrm{T} \leq 4 \mathrm{~cm}$ with MEE) did not compromise the survival compared to Group $1(\mathrm{~T} \leq 4 \mathrm{~cm}$ without MEE) (HR: 0.98, 95\% CI: (0.77-1.24), $P=0.85$ ), suggesting no effect on survival in tumors less than $4 \mathrm{~cm}$. Although their counterparts in Groups 3 and $4(\mathrm{~T}>4 \mathrm{~cm}$ with MEE) ( $\mathrm{T}>4 \mathrm{~cm}$ without MEE) had significantly lower survival in comparison with the same patients in Group 1 (T $\leq 4 \mathrm{~cm}$ without MEE) (HR: 2.44, 95\% CI: $(1.80,3.32)$, $P<0.001)$ (HR: $1.65,95 \%$ CI: $(1.28,2.14), P<0.001)$ (Fig. 1 and Table 2). Comparing 95\% CIs showed that Groups 3 and 4 have lower survival compared to Group 2 and also showed that there is an overlap between Groups 3 and $495 \%$ CIs, which indicates no significant difference in survival between the two groups. Total thyroidectomy was the preferred operation performed by surgeons in the United States compared to unilateral thyroidectomy in all four groups $(P \leq 0.001)$. In comparison with unilateral thyroidectomy, total thyroidectomy was associated with improved overall survival in Group 4 only ( $\mathrm{T}>4 \mathrm{~cm}$ without MEE) $(P=0.01)$ (Table 3). However, RAI administration was

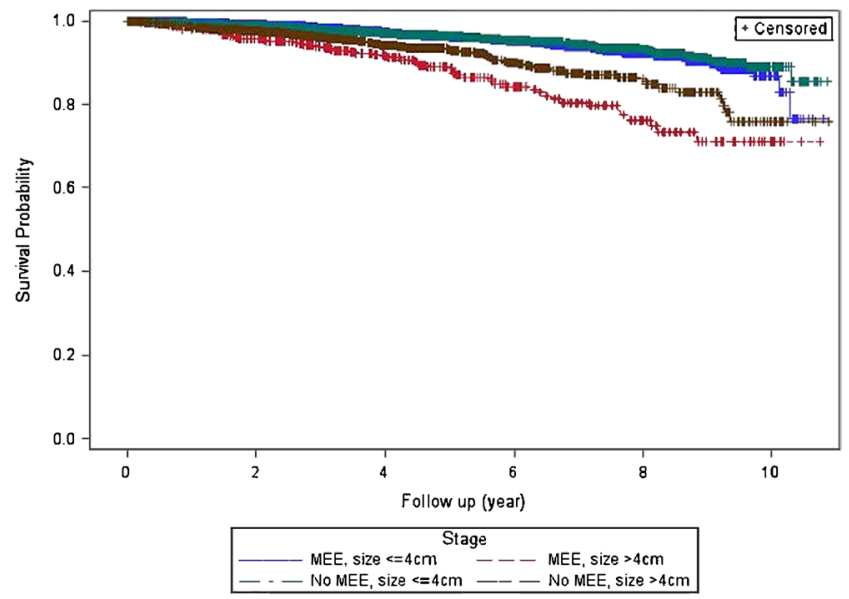

Figure 1

Kaplan-Meier curve of survival probability of patients with differentiated thyroid cancer based on stage, minimal extrathyroidal extension (MEE) status, and tumor size. A full colour version of this figure is available at http://dx.doi.org/10.1530/ERC-16-0509.

Published by Bioscientifica Ltd 
Table 2 Overall survival of patients with differentiated thyroid cancer based on stage, minimal extrathyroidal extension, and tumor size.

\begin{tabular}{|c|c|c|c|}
\hline & aHR $^{\mathbf{a}}$ & $95 \% \mathrm{Cl}$ & $\boldsymbol{P}$ \\
\hline pT2NOMO & 1 (Reference) & & \\
\hline pT3N0M0, MEE, size $\leq 4 \mathrm{~cm}$ & 0.98 & $0.77,1.24$ & 0.85 \\
\hline pT3N0M0, MEE, size $>4 \mathrm{~cm}$ & 2.44 & $1.80,3.32$ & $<0.001$ \\
\hline pT3N0M0, no MEE, size $>4 \mathrm{~cm}$ & 1.65 & $1.28,2.14$ & $<0.001$ \\
\hline
\end{tabular}

aThe model includes: age, gender, race, Charlson/Deyo score, radioactive iodine therapy status, and insurance type.

aHR, adjusted hazard ratio; $\mathrm{Cl}$, confidence interval; MEE: minimal extrathyroidal extension.

associated with improved survival in tumors larger than $4 \mathrm{~cm}$ in Group 3 (T $>4 \mathrm{~cm}$ with MEE) (HR: $0.57,95 \% \mathrm{CI}$ : (0.33-0.97), $P=0.0387$ ) and in Group $4(\mathrm{~T}>4 \mathrm{~cm}$ without MEE) (HR: 0.58, 95\% CI: (0.38-0.87), $P=0.008)$ (Table 3).

\section{Discussion}

Our results demonstrated that MEE of DTC is not a poor prognostic factor in most thyroid cancer patients. MEE does not influence survival in DTC patients older than 45 years, with $\leq 4 \mathrm{~cm}$ and NO. To our knowledge, this is the largest series to investigate the impact of MEE on survival in this group of patients. This finding is especially important given the less aggressive approach to tumors less than $4 \mathrm{~cm}$ recommended by the most recent ATA thyroid cancer guidelines (Haugen et al. 2016). The finding of MEE in this population should not lead to more aggressive surgical or RAI treatment.
Other recent studies agree with our findings and support the drop of MEE in the awaited 8th edition of the American Joint Committee on Cancer (AJCC) staging system (Table 4) (Amin et al. 2017). These were all retrospective single institution studies (Ito et al. 2006b, Chereau et al. 2014, Hay et al. 2016), except for Hotomi and coworkers, which was a prospective study including 930 Japanese patients (Hotomi et al. 2012).

Historically, Mazaferri recommended that total thyroidectomy decreases the risk of recurrence compared to thyroid lobectomy and possibly improve survival (Mazzaferri et al. 1977, Mazzaferri \& Young 1981). Our study showed that surgeons in the United States performed more total thyroidectomy than lobectomy for these patients. Our findings demonstrated survival improvement with total thyroidectomy for some tumors over $4 \mathrm{~cm}$. There was no survival improvement with total thyroidectomy for any tumors under $4 \mathrm{~cm}$ in our study. These findings again support the recent ATA thyroid cancer guidelines suggesting less aggressive treatment is warranted in this patient population with DTC less than $4 \mathrm{~cm}$ (Haugen et al. 2016).

MEE appears to affect the decisions involving the extent of resection and RAI adjuvant treatment in the United States (Haugen et al. 2016). In our study, total thyroidectomy was more likely to be performed in Group $2(\mathrm{~T} \leq 4 \mathrm{~cm}$ with MEE) than that in Group $1(\mathrm{~T} \leq 4 \mathrm{~cm}$ without MEE). Only 4 studies did question the modality of treatment between the 2 groups (Moon et al. 2011, Nixon et al. 2011, Shin et al. 2013, Radowsky et al. 2014).

Table 3 Overall survival of patients with differentiated thyroid cancer for selected stage based on management received.

\begin{tabular}{|c|c|c|c|c|}
\hline Stage & Factor & $\mathbf{a H R}^{\mathbf{a}}$ & $95 \% \mathrm{Cl}$ & $\boldsymbol{P}$ \\
\hline \multirow[t]{4}{*}{ pT2NOMO } & Unilateral thyroidectomy & 1 (Reference) & & \\
\hline & Total thyroidectomy & 0.85 & $0.57,1.28$ & 0.44 \\
\hline & RAI not received & 1 (Reference) & & \\
\hline & RAI received & 0.85 & $0.60,1.19$ & 0.34 \\
\hline \multirow[t]{4}{*}{ pT3NOM0, MEE, size $\leq 4 \mathrm{~cm}$} & Unilateral thyroidectomy & 1 (Reference) & & \\
\hline & Total thyroidectomy & 0.67 & $0.40,1.14$ & 0.14 \\
\hline & RAI not received & 1 (Reference) & & \\
\hline & RAI received & 0.83 & $0.57,1.23$ & 0.36 \\
\hline \multirow[t]{4}{*}{ pT3NOM0, MEE, size $>4 \mathrm{~cm}$} & Unilateral thyroidectomy & 1 (Reference) & & \\
\hline & Total thyroidectomy & 1.03 & $0.54,1.94$ & 0.93 \\
\hline & RAI not received & 1 (Reference) & & \\
\hline & RAI received & 0.57 & $0.33,0.97$ & 0.039 \\
\hline \multirow[t]{4}{*}{ pT3NOM0, no MEE, size $>4 \mathrm{~cm}$} & Unilateral thyroidectomy & 1 (Reference) & & \\
\hline & Total thyroidectomy & 0.56 & $0.36,0.87$ & 0.010 \\
\hline & RAI not received & 1 (Reference) & & \\
\hline & RAI received & 0.58 & $0.38,0.87$ & 0.008 \\
\hline
\end{tabular}

aThe model includes age, gender, race, Charlson/Deyo score, type of thyroidectomy, radioactive iodine therapy status, hospital volume and insurance type.

aHR, adjusted hazard ratio; $\mathrm{Cl}$, confidence interval; $\mathrm{MEE}$, minimal extrathyroidal extension; RAI, radioactive iodine.

http://erc.endocrinology-journals.org DOI: $10.1530 /$ ERC-16-0509
C 2017 Society for Endocrinology Printed in Great Britain
Published by Bioscientifica Ltd. 
Similar to Nixon, we demonstrated that total thyroidectomy was not associated with better survival in Group 2 ( $\mathrm{T} \leq 4 \mathrm{~cm}$ with MEE) (Nixon et al. 2011).

We demonstrated that MEE with small tumor size $\leq 4 \mathrm{~cm}$ (Group 2) did not have any greater risk of mortality when compared with Stage II patients in (Group 1). However, in patients with large tumors $>4 \mathrm{~cm}$ (Groups 3 and 4 ), overall survival was significantly affected.

Our study has limitations, some of which are anticipated with the use of any administrative database, which allows the potential for coding error. Information regarding disease-specific survival data is not available in NCDB. Nonetheless, the data have several strengths including the large sample size and specific details regarding clinical and pathological features. We recognize a further issue is that pathologic definition of minimal extrathyroidal extension may vary from pathologist to pathologist. We also recognize that our findings only apply to patients aged older than 45 years. Furthermore, we cannot explain why total thyroidectomy appeared to improve survival only in Group 4 but not in Group 3. It is of note, however, that RAI improves survival in all patients with large tumors greater than $4 \mathrm{~cm}$.

\section{Conclusions}

Patients with DTC aged older than 45 years of age associated with MEE, and tumor size $\leq 4 \mathrm{~cm}$, had similar survival of patients with Stage II. Total thyroidectomy did not add any survival benefit in this group. Our data support re-evaluation of the current ATA risk stratification and AJCC staging systems. The ATA risk stratification should consider stratification of the MEE into 2 groups: MEE with small size nodule $\leq 4$ in the lowrisk group and MEE with large size nodule $>4 \mathrm{~cm}$ in the intermediate-risk group. Accordingly, physicians should not over treat Stage II (DTC) associated with MEE by completion thyroidectomy and RAI ablation.

Declaration of interest

The authors declare that there is no conflict of interest that could be perceived as prejudicing the impartiality of the research reported.

Funding

This research did not receive any specific grant from any funding agency in the public, commercial or not-for-profit sector.

Author contribution statement

Study conception and design: Al-Qurayshi, Shama and Kandil. Acquisition of data: Al-Qurayshi, Shama and Kandil. Analysis and interpretation of 
data: Shama and Al-Qurayshi. Drafting of manuscript: Shama, Al-Qurayshi, Randolph and Kandil. Critical revision: Al-Qurayshi, Shama, Randolph and Kandil.

\section{References}

Amin MB, Edge S, Greene F, Byrd DR, Brookland RK, Washington MK, Gershenwald JE, Compton CC, Hess KR, Sullivan DC, et al. 2017 AJCC Cancer Staging Manual, 8th ed, 1024. Cham, Switzerland: Springer International Publishing.

Chereau N, Buffet C, Tresallet C, Tissier F, Golmard JL, Leenhardt L \& Menegaux F 2014 Does extracapsular extension impact the prognosis of papillary thyroid microcarcinoma? Annals of Surgical Oncology 21 1659-1664. (doi:10.1245/s10434-013-3447-y)

Edge SBBD \& Carducci MA 2009 American Joint Committee on Cancer (AJCC) Cancer Staging Manual. New York, NY, USA: Springer.

Haugen BR, Alexander EK, Bible KC, Doherty GM, Mandel SJ, Nikiforov YE, Pacini F, Randolph GW, Sawka AM, Schlumberger M, et al. 20162015 American Thyroid Association Management Guidelines for adult patients with thyroid nodules and differentiated thyroid cancer: the American Thyroid Association Guidelines task force on thyroid nodules and differentiated thyroid cancer. Thyroid 26 1-133. (doi:10.1089/thy.2015.0020)

Hay ID, Johnson TR, Thompson GB, Sebo TJ \& Reinalda MS 2016 Minimal extrathyroid extension in papillary thyroid carcinoma does not result in increased rates of either cause-specific mortality or postoperative tumor recurrence. Surgery 159 11-19. (doi:10.1016/j. surg.2015.05.046)

Hotomi M, Sugitani I, Toda K, Kawabata K \& Fujimoto Y 2012 A novel definition of extrathyroidal invasion for patients with papillary thyroid carcinoma for predicting prognosis. World Journal of Surgery 36 1231-1240. (doi:10.1007/s00268-012-1518-z)

Ito Y, Tomoda C, Uruno T, Takamura Y, Miya A, Kobayashi K, Matsuzuka F, Kuma K \& Miyauchi A 2006a Minimal extrathyroid extension does not affect the relapse-free survival of patients with papillary thyroid carcinoma measuring $4 \mathrm{~cm}$ or less over the age of 45 years. Surgery Today 36 12-18. (doi:10.1007/s00595-005-3090-8)

Ito Y, Tomoda C, Uruno T, Takamura Y, Miya A, Kobayashi K, Matsuzuka F, Kuma K \& Miyauchi A 2006b Prognostic significance of extrathyroid extension of papillary thyroid carcinoma: massive but not minimal extension affects the relapse-free survival. World Journal of Surgery 30 780-786. (doi:10.1007/s00268-005-0270-z)

Ito Y, Kudo T, Kobayashi K, Miya A, Ichihara K \& Miyauchi A 2012 Prognostic factors for recurrence of papillary thyroid carcinoma in the lymph nodes, lung, and bone: analysis of 5768 patients with average 10-year follow-up. World Journal of Surgery 36 1274-1278. (doi:10.1007/s00268-012-1423-5)
Machens A \& Dralle H 2015 Breach of the thyroid capsule and lymph node capsule in node-positive papillary and medullary thyroid cancer: different biology. European Journal of Surgical Oncology 41 766-772. (doi:10.1016/j.ejso.2014.10.049)

Mazzaferri EL \& Young RL 1981 Papillary thyroid carcinoma: a 10 year follow-up report of the impact of therapy in 576 patients. American Journal of Medicine 70 511-518. (doi:10.1016/00029343(81)90573-8)

Mazzaferri EL, Young RL, Oertel JE, Kemmerer WT \& Page CP 1977 Papillary thyroid carcinoma: the impact of therapy in 576 patients. Medicine 56 171-196. (doi:10.1097/00005792-197705000-00001)

Moon HJ, Kim EK, Chung WY, Yoon JH \& Kwak JY 2011 Minimal extrathyroidal extension in patients with papillary thyroid microcarcinoma: is it a real prognostic factor? Annals of Surgical Oncology 18 1916-1923. (doi:10.1245/s10434-011-1556-z)

Nixon IJ, Ganly I, Patel S, Palmer FL, Whitcher MM, Tuttle RM, Shaha AR \& Shah JP 2011 The impact of microscopic extrathyroid extension on outcome in patients with clinical T1 and T2 welldifferentiated thyroid cancer. Surgery 150 1242-1249. (doi:10.1016/j. surg.2011.09.007)

Radowsky JS, Howard RS, Burch HB \& Stojadinovic A 2014 Impact of degree of extrathyroidal extension of disease on papillary thyroid cancer outcome. Thyroid 24 241-244. (doi:10.1089/thy.2012.0567)

Ruel E, Thomas S, Dinan MA, Perkins JM, Roman SA \& Sosa JA 2016 Knowledge of pathologically versus clinically negative lymph nodes is associated with reduced use of radioactive iodine postthyroidectomy for low-risk papillary thyroid cancer. Endocrine $\mathbf{5 2}$ 579-586. (doi:10.1007/s12020-015-0826-0)

Shin JH, Ha TK, Park HK, Ahn MS, Kim KH, Bae KB, Kim TH, Choi CS, Kim TK, Bae SK, et al. 2013 Implication of minimal extrathyroidal extension as a prognostic factor in papillary thyroid carcinoma. International Journal of Surgery 11 944-947. (doi:10.1016/j. ijsu.2013.06.015)

Sugitani I, Kasai N, Fujimoto Y \& Yanagisawa A 2004 A novel classification system for patients with PTC: addition of the new variables of large (3 cm or greater) nodal metastases and reclassification during the follow-up period. Surgery 135 139-148. (doi:10.1016/S0039-6060(03)00384-2)

Verburg FA, Mader U, Tanase K, Thies ED, Diessl S, Buck AK, Luster M \& Reiners C 2013 Life expectancy is reduced in differentiated thyroid cancer patients \&gt;/= 45 years old with extensive local tumor invasion, lateral lymph node, or distant metastases at diagnosis and normal in all other DTC patients. Journal of Clinical Endocrinology and Metabolism 98 172-180. (doi:10.1210/jc.2012-2458)

Woolner LB, Beahrs OH, Black BM, Mc CW \& Keating FR Jr 1961 Classification and prognosis of thyroid carcinoma. A study of 885 cases observed in a thirty year period. American Journal of Surgery 102 354-387. (doi:10.1016/0002-9610(61)90527-X)

Received in final form 4 February 2017

Accepted 1 March 2017

Accepted Preprint published online 1 March 2017
๑ 2017 Society for Endocrinology Printed in Great Britain
Published by Bioscientifica Ltd. 